\title{
Kinetic Investigations on Dyeing of Different Polyester Fabrics Using Microwave Irradiation
}

\author{
N. S. Elshemy ${ }^{1 *}$, M. H. Elshakankery ${ }^{1}$, S. M. Shahien ${ }^{2}$, K. Haggag $^{1}$ and H. El- \\ Sayed $^{1}$ \\ ${ }^{1}$ Textile Research Division, National Research Center, 33 Tahrir St., 12311-Dokki, Cairo, Egypt \\ ${ }^{2}$ Clothing \& Textile Department, Faculty of Home Economics, Menofia University, Egypt.
}

\begin{abstract}
$\mathbf{T}$ HERE are several factors affecting physical and mechanical properties of the woven polyester fabrics, from these factors different weave constructions. The goal of this research is to study the effect of using different polyester fabric constructions on dyeing process via microwave irradiation. The resulted change in dye absorption, dyeing time and dyeing temperature were investigated. The fabric characteristics; namely tensile strength, elongation, and color fastness properties were also studied. The percentage dye exhaustion, dye fixation ratio and total dye fixation were evaluated. Dyeing rate constant, half dyeing time, activation energy and dye affinity of the different polyester fabric structures were calculated. The results this investigation proved that use of microwave irradiation brings about improvement in the quality of dyed fabric uniformity and color fastness properties. The woven polyester fabrics dyed with disperse dye and subjected to microwave irradiation for $50 \mathrm{~min}$. at $100^{\circ} \mathrm{C}$ at different dye concentration increased dye concentration, and consequently enhanced the color strength for all the dyed samples. Fabric cover factor has significant effect on fabric strength as compared with other dependent variables.
\end{abstract}

Keywords: Microwave, Woven polyester, Fabric construction, Dyes, Disperse dye.

\section{Introduction}

Throughout the last years, amendments and coloring of a few materials have been directed under microwave irradiation condition [1]. Microwave irradiation is one of vigorous techniques of non-contact heating, on the grounds that the dielectric substances with huge dielectric loss consistent energetically fever by vibration and revolution of changeless dipoles in microwave field. Microwave has been utilized for responding, warming, coloring and drying of different materials, since microwave irradiation was found to quicken surprisingly a wide assortment of responses.

The microwave irradiation has been utilized as a part of the coloring processing of polyester fabric. In the traditional heating of fabric, a lot of vitality is devoured. Some new procedures and techniques for saving energy and time were researched [2-
4]. Microwave heating, as a different option for customary heating procedure, has been turned out to be more quick, uniform and proficient. The microwave energy can enter to molecule inside and all particles can be warmed instantaneously, in this way reducing heat transfer problems.

However, the microwave irradiation could influence the chemical and morphological structure of different materials, including some physical properties $[5,6]$. The report of the impact of microwave light and material structure on the coloring and physical properties of polyester fabric was rare.

On the other hand, fabric construction is related to fabric properties. Therefore designers can construct fabrics with determined properties for certain end use. The cover factor defines the area of a fabric which is really covered by ends and picks yarns [7]. 
The main target of this work to create method appropriate for coloring customary and carrierless dyeable woven polyester fabric with a disperse dyestuff by utilizing microwave irradiation. The aim of this work is extended to study the impact of various factors of coloring procedures regarding of uniformity, color penetration, and color diffusion. The tensile strength, elongation and fastness properties of the colored woven polyester fabrics were additionally investigated.

\section{Experimental}

\section{Materials}

Woven polyester fabrics with different structure, as shown in the following table, supplied from Misr Co., El Mehalla El-Kubra, Egypt, for spinning and weaving, were used.
Fabric cover factor $K$ (Pierce)

$K=\frac{e \cdot p \cdot i}{\sqrt{N_{e 1}}}+\frac{p \cdot p \cdot i}{\sqrt{N_{e 2}}}-\left(\left(\frac{e \cdot p \cdot i}{\sqrt{N_{e 1}}} x \frac{p \cdot p \cdot i}{\sqrt{N_{e 2}}}\right) / 28\right) \ldots \ldots$

where:

e.p.i $=$ ends per inch

p.p.i $=$ picks per inch.

$\mathrm{N}_{\mathrm{e} 1}, \mathrm{~N}_{\mathrm{e} 2}=$ ends and picks English count.

Dyes

Commercial disperses dye namely Suncron Orange 3, was kindly supplied from ICI company.

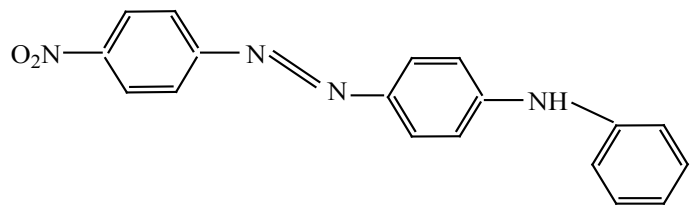

TABLE 1. Fiber structure of woven polyester fabric.

\begin{tabular}{lccc}
\hline Polyester fabric code & 4228 & 5106 & 4181 \\
\hline Raw samples weight $\mathrm{g} / \mathrm{m}^{2}$ & 175 & 174 & 170 \\
Finishing samples weight $\mathrm{g} / \mathrm{m}^{2}$ & 150 & 166 & 158 \\
Weft density / inch & 65 & 75 & 56 \\
Warp density / inch & 163 & 156 & 254 \\
Raw fabric width cm. & 128 & 138 & 128 \\
Bleaching fabric width cm & 115 & 130 & 115 \\
Warp yarns count (detex) & $135 / 108$ & $150 / 48$ & $50 / 24$ \\
Weft yarns count (detex) & $150 / 48$ & $150 / 48$ & $300 / 96$ \\
Twists/m for weft yarns & 1800 & 1000 & - \\
Weave structure & Plain weave & Twill $2 / 2$ & satin 4 \\
\hline
\end{tabular}

\section{Reagents}

Acetic acid, sodium bicarbonate and sodium hydroxide of laboratory grade were purchased from Adwic, Cairo, Egypt.

\section{Dyeing process}

The dyeing process was applied to the fabric via exhaustion technique using microwave irradiation. The woven polyester fabrics were immersed in the dye bath $(0.5-3.5 \%$ shade $)$ at different temperature $\left(60,80,100^{\circ} \mathrm{C}\right)$, liquor ratio being 1:50, $\mathrm{pH}$ 5-5.5 for different time (10-60 min.). After dyeing, the fabrics were removed, rinsed and dried at room temperature.

\section{Exhaustion and Fixation \% measurement}

The reflectance of dyed fabric was measured on reflectance spectro-photometer Model IcsTexicon Ltd. The percentage of dye exhaustion

Egypt.J.Chem. Special Issue (2017)
$(\mathrm{E} \%)$ was calculated according to Eqn. 1:

$$
E \%=\llbracket A_{0}-A_{f} / A_{0} \rrbracket \times 100
$$

Where $A_{0}$ and $A_{f}$ are the absorbance of the dyebath before and after dyeing, respectively, at $\lambda$ max of the dye $(470 \mathrm{~nm})$. The absorbance was measured on a Shimadzu UV-2401 PC UV/Vis spectrophotometer

The concentration of the dye in the fiber (mg/g) was determined using Eqn. 2:

$$
D_{f}=\left(D_{0}-D_{s}\right) V / W
$$

Where $D_{0}$ is the dye concentration in fiber $(\mathrm{mg} / \mathrm{g})$, and $D_{s}$ is the initial and equilibrium concentration of dye in the dyebath $(\mathrm{mg} / \mathrm{L})$, 
respectively, (L) is the volume of dyebath and $(\mathrm{g})$ is the weight of fiber. The dye solution concentrations were determined after reference to the respective calibration curve using LambertBeer law.

The extent of dye fixation ratio of Suncron Orange $3(220 \%)$ on polyester fabric was determined by measuring K/S values of the dyed samples before and after soaping using Eqn. 3:

$\mathrm{F} \%=\frac{(\mathrm{K} / \mathrm{S})_{\text {after soaping }}}{(\mathrm{K} / \mathrm{S})_{\text {before soaping }}} \times 100 \ldots \ldots$.

From the result of the $(\mathrm{E} \%)$ and $(\mathrm{F} \%)$, the total dye fixation (T\%), was calculated using Eqn. 4:

$\mathrm{T} \%=(\mathrm{E} \% \times \mathrm{F} \%) / 100$

\section{Physical property measurements}

Ten specimens (five for warp and five for weft) were tested. The tensile and elongation properties of the fabric were measured according to ISO13934.1-1994.

Color fastness properties measurements and testing

The color strength of the dyed samples was evaluated by Hunter lab Ultra scan PRO. The color strength, expressed as K/S and the overall fastness properties (washing, perspiration and crocking) were assessed according to the standard methods [8-11].

\section{Results and Discussion}

Effect of dyeing time and temperature

In microwave operation, energy is provided by an "electromagnetic field" precisely to the substance. Volumetric warming can minimize the required energy and time of dyeing. The

TABLE 1: Fiber structure of woven polyester fabric. microwave field and the dielectric reaction of a substance oversee the capacity to energy with microwave irradiation. Learning of magnetic hypothesis and dielectric reaction is vital to enhance the treatment of materials through microwave warming $[12,13]$.

In certainty the magnetic field part of microwave radiation is responsible for dielectric heating technique since it might bring about particles movement by either moving of symbols species (conduction framework) or dipolar turn (dipolar polarization component). The dielectric property refers to the characteristic electrical properties that influence the shading by dipolar revolution of the shading and influences the microwave field upon the dipoles, in the high frequency microwave filed vacillating at $2450 \mathrm{MHz}$. It influences the vibrational energy in water particles and the dye molecules. The heating component is through ionic conduction, which is a sort of resistance heating. Depending on the expanding velocity of the particles through the shading plan, it results in impact of shading atoms with the fiber particle. The microwave radiation helps and influences the penetration of the shading furthermore the depth to which the infiltration happens in the fabric. This improves microwave than conventional shading methodology [12].

Coloring of polyester fabric with disperse dye namely Suncron Orange3 under the effect of microwave irradiation have been investigated. Based on trials the results showed that, the microwave heating could be shortened coloring time and saved energy amazingly.

To achieve this goal three different structures of woven polyester fabrics were selected (see Table 1). Dyeing bath was prepared as indicated in the recipe described in the experimental part. The specimen of different woven polyester fabrics were dyed

\begin{tabular}{lccc}
\hline Polyester fabric code & 4228 & 5106 & 4181 \\
\hline Raw samples weight $\mathrm{g} / \mathrm{m}^{2}$ & 175 & 174 & 170 \\
Finishing samples weight $\mathrm{g} / \mathrm{m}^{2}$ & 150 & 166 & 158 \\
Weft density / inch & 65 & 75 & 56 \\
Warp density / inch & 163 & 156 & 254 \\
Raw fabric width cm. & 128 & 138 & 128 \\
Bleaching fabric width cm & 115 & 130 & 115 \\
Warp yarns count (detex) & $135 / 108$ & $150 / 48$ & $50 / 24$ \\
Weft yarns count (detex) & $150 / 48$ & $150 / 48$ & $300 / 96$ \\
Twists/m for weft yarns & 1800 & 1000 & - \\
Weave structure & Plain weave & Twill 2/2 & satin 4 \\
\hline
\end{tabular}


through exhaustion processes by using microwave irradiation under different conditions namely dyeing time, temperature as well as dye concentration. After dyeing, the fabric samples were subjected to washing then dried at the ambient temperature and estimate for $\mathrm{K} / \mathrm{S}$, kinetic study and overall fastness properties.

Table 2-4 comprise the results obtained for the samples dyed with Suncron Orange 3by using microwave irradiation at various time (10$60 \mathrm{~min}$.) at constant microwave power of $500 \mathrm{~W}$,
$1 \%$ shade and $\mathrm{pH} 5$. From the information data in table 2 It was obvious that, as the dyeing time and dyeing temperature increase the $\mathrm{K} / \mathrm{S}$ of the dyed different woven polyester fabrics increases orderly (from 2.91 to 9.81). Furthermore, the same pattern was seen from the information of Table 3 and Table 4.This may be attributed to the effect of microwave irradiation which causes fiber swelling that leads to enhancing the dye penetration into the fiber.

TABLE 2. Effect of temperature and dyeing time on color strength of woven polyester (5106) fabric dyed with disperse dye by using microwave irradiation.

\begin{tabular}{|c|c|c|c|c|c|c|}
\hline \multirow{3}{*}{$\begin{array}{l}\text { Dyeing } \\
\text { time/min. }\end{array}$} & \multicolumn{6}{|c|}{ Color strength K/S } \\
\hline & \multicolumn{2}{|c|}{$60^{\circ} \mathrm{C}$} & \multicolumn{2}{|c|}{$80^{\circ} \mathrm{C}$} & \multicolumn{2}{|c|}{$100^{\circ} \mathrm{C}$} \\
\hline & Weft & Warp & Weft & Warp & Weft & Warp \\
\hline 10 & 0.44 & 0.39 & 1.14 & 0.69 & 2.07 & 2.91 \\
\hline 20 & 0.45 & 0.51 & 1.23 & 1.47 & 3.10 & 6.23 \\
\hline 30 & 0.49 & 0.52 & 1.33 & 1.96 & 6.42 & 6.86 \\
\hline 40 & 0.57 & 0.61 & 3.12 & 2.01 & 6.86 & 8.60 \\
\hline 50 & 0.63 & 0.65 & 3.53 & 3.31 & 8.87 & 9.80 \\
\hline 60 & 0.63 & 0.65 & 3.53 & 3.65 & 8.88 & 9.81 \\
\hline
\end{tabular}

$1 \%$ shad, power level 500 watt, $\mathrm{pH}=5$, at different time and different temperature.

TABLE 3. Effect of temperature and dyeing time on color strength of woven polyester (4181) fabric dyed with disperse dye by using microwave irradiation.

\begin{tabular}{ccccccc}
\hline \multirow{2}{*}{$\begin{array}{c}\text { Dyeing } \\
\text { time/min. }\end{array}$} & \multicolumn{7}{c}{ Color strength K/S } \\
\cline { 2 - 7 } & \multicolumn{2}{c}{$\mathbf{6 0}^{\circ} \mathbf{C}$} & \multicolumn{2}{c}{$\mathbf{8 0}^{\circ} \mathbf{C}$} & & $\mathbf{1 0 0}^{\circ} \mathbf{C}$ \\
\hline 10 & Weft & Warp & Weft & Warp & Weft & Warp \\
\hline 20 & 0.32 & 0.34 & 0.67 & 1.14 & 4.76 & 4.19 \\
\hline 30 & 0.34 & 0.36 & 1.22 & 1.17 & 4.98 & 4.21 \\
\hline 40 & 0.35 & 0.45 & 1.62 & 2.72 & 6.62 & 6.79 \\
\hline 50 & 0.36 & 0.46 & 2.36 & 2.38 & 8.09 & 7.91 \\
\hline 60 & 0.75 & 0.76 & 3.58 & 4.98 & 8.64 & 8.77 \\
\hline $1 \% 5$ & 0.75 & 0.77 & 3.7 & 4.98 & 8.64 & 8.79 \\
\hline
\end{tabular}

$1 \%$ shad, power level 500 watt, $\mathrm{pH}=5$, at different time and different temperature.

TABLE 4. Effect of temperature and dyeing time on color strength of woven polyester (4228) fabric dyed with disperse dye using microwave irradiation.

\begin{tabular}{|c|c|c|c|c|c|c|}
\hline \multirow{3}{*}{$\begin{array}{l}\text { Dyeing } \\
\text { time/min. }\end{array}$} & \multicolumn{6}{|c|}{ Color strength $\mathrm{K} / \mathrm{S}$} \\
\hline & \multicolumn{2}{|c|}{$60^{\circ} \mathrm{C}$} & \multicolumn{2}{|c|}{$80^{\circ} \mathrm{C}$} & \multicolumn{2}{|c|}{$100^{\circ} \mathrm{C}$} \\
\hline & Weft & Warp & Weft & Warp & Weft & Warp \\
\hline 10 & 1.00 & 0.98 & 2.64 & 2.83 & 10.87 & 11.80 \\
\hline 20 & 1.12 & 1.03 & 4.27 & 3.87 & 11.93 & 13.47 \\
\hline 30 & 1.03 & 1.04 & 4.39 & 5.05 & 18.79 & 16.91 \\
\hline 40 & 1.11 & 1.15 & 6.14 & 5.60 & 18.89 & 19.41 \\
\hline 50 & 1.38 & 1.56 & 10.30 & 13.59 & 20.61 & 21.53 \\
\hline 60 & 1.38 & 1.56 & 10.57 & 14.14 & 20.61 & 21.64 \\
\hline
\end{tabular}

$1 \%$ shad, power level 500 watt, $\mathrm{pH}=5$, at different time and different temperature.

Egypt.J.Chem. Special Issue (2017) 
TABLE 5. Effect of dye concentration on color strength of different woven polyester fabrics dyed with Suncron Orange 3 dye by using microwave irradiation.

\begin{tabular}{ccccccc}
\hline Dye conc. $\mathbf{~ m g / g}$ & \multicolumn{7}{c}{ Color strength K/S } \\
\cline { 2 - 7 } & \multicolumn{2}{c}{$\mathbf{5 1 0 6}$} & \multicolumn{2}{c}{$\mathbf{4 1 8 1}$} & 4228 \\
\cline { 2 - 7 } & Weft & Warp & Weft & Warp & Weft & Warp \\
\hline 0.5 & 2.1 & 3.5 & 1.8 & 2.2 & 8.8 & 9.9 \\
1.0 & 4.7 & 5.8 & 4.1 & 5.1 & 13.4 & 14.5 \\
1.5 & 6.2 & 7.9 & 5.4 & 7.0 & 16.7 & 18.8 \\
2.0 & 8.87 & 9.8 & 8.64 & 8.77 & 20.6 & 21.53 \\
2.5 & 10.3 & 11.1 & 9.5 & 10.1 & 23.2 & 23.7 \\
3.0 & 11.5 & 12.9 & 9.5 & 10.1 & 23.4 & 24.4 \\
3.5 & 11.5 & 12.9 & 9.5 & 10.1 & 23.4 & 24.4 \\
\hline
\end{tabular}

Power level 500 watt, $\mathrm{pH}=5,50$ min.at $100^{\circ} \mathrm{C}$ at different concentration.

Table 5 manifest the K/S of woven polyester specimen dyed by disperse dye then exposed to microwave irradiation aimed to $50 \mathrm{~min}$. at $100^{\circ} \mathrm{C}$ at various dye concentration $(0.5-3.5 \%$ shade). It is clear from the data that, increasing dye concentration is attendant by raise in the K/S for all the samples.

\section{Kinetics studies}

The rate of reaction is communicated as the variation in reaction concentration with time. Accordingly, observing the change in dye exhaustion with time prompts an evaluation of the coloring kinetics for certain procedure.

Time exhaustion of different woven polyester fabric colored with Suncron Orange 3 at $80^{\circ} \mathrm{C}$ and $100^{\circ} \mathrm{C}$ is shown in Fig. 1. The results show that the exhaustion follows the order: $4228>4181>5106$.

In all items, the behavior of the coloring isotherm shows early saturation, independent of the structure of the fabric or the temperature utilized. The information in Fig. 1 can be analyzed by utilizing Eqn. 5:

$A_{t}-A_{f} / A_{0}-A_{f}=Q e^{-k t}$
Where $K$ is the kinetic consistent relational to the dispersion coefficient, $Q$ Is the coefficient reliant on equipoise exhaustion, $\boldsymbol{A}_{\boldsymbol{t}}$ is the dyebath absorbance at time, is the first absorbance, $A_{0}$ is the last absorbance and $A_{f}$ is the coloring time. This equation is relevant for center and last stage of coloring and contemplates the main term of the limitless whole of general solution for portraying the diffusion into the fiber.

Taking the logarithm of Eqn. 5 would lead to Eqn. 6 and since $A_{f}$ is known so $A_{t}-A_{f}$ can be calculated.

$\ln \left(A_{t}-A_{f} / A_{0}-A_{f}\right)=\ln Q^{-k t}$

A plot of $\ln \left(A_{t}-A_{f} / A_{0}-A_{f}\right)$ vs. time is expected to be linear with a slop of-k. The values of the dyeing rate constant are lasted in Table 6.

Table 6 depicts the effect of microwave irradiation on the Exhaustion \% as well as the total fixation $\%$ of different structure of woven polyester fabrics dyed with Suncron3 orange. From the table we noticed that as the dyeing time increase the $\mathrm{E} \%$ as well as $\mathrm{T} \%$ increase until

TABLE 6. Effect of coloring time on Exhaustion and total fixation of Suncron Orange 3 for different structure of woven polyester fabrics dyed with $\mathrm{MH}$.

\begin{tabular}{|c|c|c|c|c|c|c|c|c|c|c|c|c|}
\hline \multirow{3}{*}{$\begin{array}{c}\text { Dyeing time/ } \\
\text { min }\end{array}$} & \multicolumn{4}{|c|}{5106} & \multicolumn{4}{|c|}{4181} & \multicolumn{4}{|c|}{4228} \\
\hline & \multicolumn{2}{|c|}{ Weft } & \multicolumn{2}{|c|}{ Warp } & \multicolumn{2}{|c|}{ Weft } & \multicolumn{2}{|c|}{ Warp } & \multicolumn{2}{|c|}{ Weft } & \multicolumn{2}{|c|}{ Warp } \\
\hline & E\% & T\% & E\% & $\mathrm{T} \%$ & E\% & T\% & E\% & $\mathrm{T} \%$ & E\% & $\mathrm{T} \%$ & E\% & T\% \\
\hline 5 & 20 & 15.8 & 29.5 & 22.84 & 16.6 & 11.29 & 19.3 & 14.39 & 24.4 & 19.83 & 30.3 & 25.20 \\
\hline 10 & 23.2 & 18.62 & 33.1 & 27.03 & 18.4 & 14.41 & 26.7 & 21.50 & 29.7 & 24.14 & 45.4 & 40.93 \\
\hline 15 & 28.1 & 24.13 & 49.1 & 42.39 & 23.6 & 19.57 & 39.4 & 33.40 & 44.6 & 41.23 & 63.8 & 60.37 \\
\hline 20 & 38.4 & 33.11 & 55.7 & 54.03 & 35.6 & 29.52 & 48.8 & 46.38 & 59.8 & 58.27 & 87.1 & 85.32 \\
\hline 25 & 42.5 & 41.02 & 55.7 & 54.03 & 40.12 & 38.01 & 48.8 & 46.38 & 59.8 & 58.27 & 87.1 & 85.32 \\
\hline 30 & 42.5 & 41.02 & 55.7 & 54.03 & 40.12 & 38.01 & 48.8 & 46.38 & 59.8 & 58.27 & 87.1 & 85.32 \\
\hline 35 & 42.5 & 41.02 & 55.7 & 54.03 & 40.12 & 38.01 & 48.8 & 46.38 & 59.8 & 58.27 & 87.1 & 85.32 \\
\hline 40 & 42.5 & 41.02 & 55.7 & 54.03 & 40.12 & 38.01 & 48.8 & 46.38 & 59.8 & 58.27 & 87.1 & 85.32 \\
\hline
\end{tabular}


25 min.in both fabric (5106 and 4181) while until $20 \mathrm{~min}$ in case of 4228. This may be due to the structure of the fabric from one hand and microwave irradiation on the second hand. This may be attributed to microwave irradiation. The microwave radiation helps and influences on the penetration of the dye furthermore the depth to which the infiltration happens in the fabric.

Half dyeing $t_{1 / 2}$ which is the time required for fabric to take up half amount of dye taken at equilibrium, is estimated from each isotherm directly (Fig.1\&2) and listed in Table 7.

The activation energy of dyeing can be calculated from Eqn. 7:

$$
\Delta E^{*}=\frac{R T_{1} T_{2}}{T_{2}-T_{1}} \ln \frac{k_{2}}{k_{1}} \ldots \ldots \ldots
$$

Where $k_{1}$ and $k_{2}$ are the rate constant at temperature

TABLE 7. Dyeing rate constant (K), half dyeing time () and activation energy () of the different polyester fabric.

\begin{tabular}{|c|c|c|c|c|c|c|c|c|c|c|}
\hline \multirow{2}{*}{$\begin{array}{c}\text { Polyester } \\
\text { type }\end{array}$} & \multicolumn{4}{|c|}{$\mathrm{K} \mathrm{x} 100\left(\mathrm{~min}^{-1}\right)$} & \multicolumn{4}{c|}{$t_{1 / 2}$ (min) } & \multicolumn{2}{c|}{$\Delta E^{*}(\mathrm{KJ} / \mathrm{mol})$} \\
\cline { 2 - 11 } & \multicolumn{2}{|c|}{ Weft } & \multicolumn{2}{|c|}{ Warp } & Weft & Warp & Weft & Warp & \multicolumn{1}{c|}{} \\
\cline { 2 - 11 } & $80^{\circ} \mathrm{C}$ & $100^{\circ} \mathrm{C}$ & $80^{\circ} \mathrm{C}$ & $100^{\circ} \mathrm{C}$ & \multicolumn{2}{|c|}{$80^{\circ} \mathrm{C}$} & $100^{\circ} \mathrm{C}$ & Weft & Warp \\
\hline 5106 & 19.234 & 20.684 & 24.384 & 26.485 & 12.5 & 12.5 & 12.5 & 10 & 7.3 & 10.4 \\
\hline 4181 & 18.934 & 18.795 & 21.335 & 23.135 & 15 & 10 & 12.5 & 10 & 6.5 & 10.2 \\
\hline 4228 & 27.184 & 28.635 & 34.484 & 37.585 & 12.5 & 12.5 & 10 & 10 & 9.2 & 10.8 \\
\hline
\end{tabular}

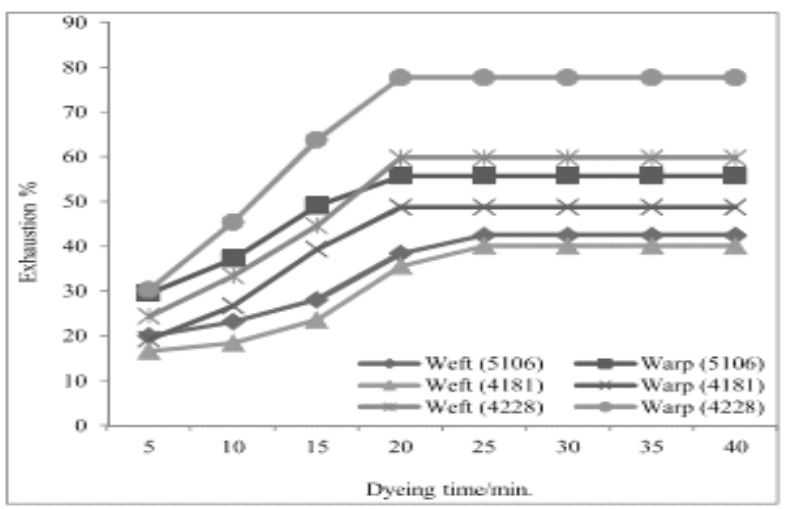

Fig.1. Sorption rate of Suncron Orange 3 for the different polyester fabric at $100^{\circ} \mathrm{C}$

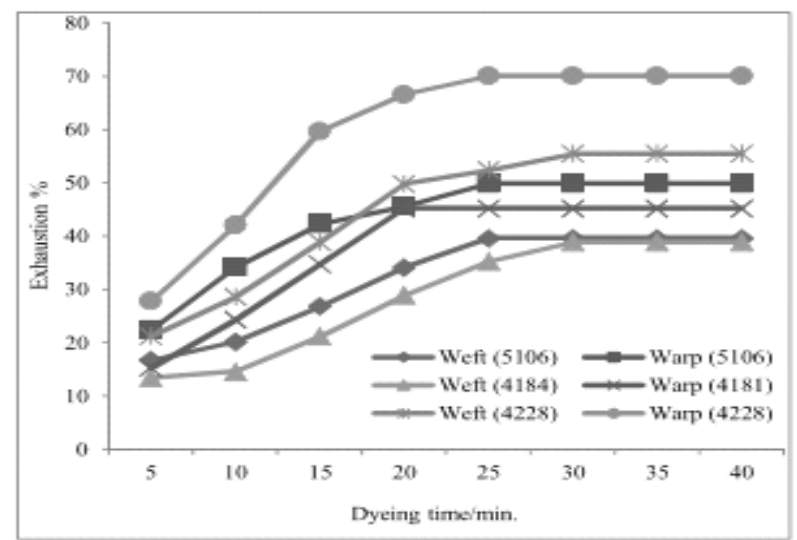

Fig.2. Sorption rate of Suncron Orange 3 for the different polyester fabric at $80^{\circ} \mathrm{C}$. 
$T_{1}$ and $T_{2}$, respectively, $R$ is the gas constant

The kinetic data using different structure of woven polyester fabrics are summarized in Table 7 , from the result it is lucid that $\Delta E^{*}$ values for the three fabrics dyed with Suncron Orange 3are ranked as follow $4228>5106>4181$. Also, it is lucid that as the coloring temperature increases the dyeing rate constant increase in an identical order.

Standard affinity is the contrast between the chemical potential of the dye in its standard state on the fiber and the corresponding chemical potential in its standard state in the dyebath. It is measure of the color propensity to move from color solution to the fiber when it's standard state in every stage. It can be calculated from Eqn.8.

$$
-\Delta \mu=R T \ln D_{f} / D_{s}
$$

Where $R$ is the gas constant, $T$ is the absolute temperature, and $D_{f}$ and $D_{s}$ are the dye concentration in the fiber and the dyebath at equilibrium respectively.

From Table 8 it can be seen that the standard affinity values of the different polyester fabric toward Suncron Orange 3are in order $4228>$ $5106>418$, this is due to fibers construction. The results also indicate that the $-\Delta \mu$ values at $80^{\circ} \mathrm{C}$ are lower than those obtained at $100^{\circ} \mathrm{C}$ which indicate that the dyeing is exothermic process.

Heat of dyeing $(\Delta \mathrm{H})$ can be calculated from Eqn. 9. The values are listed in Table 8. Enthalpy was found to have a negative values indicating that the dyeing process is exothermic one and the values follow the same order.

The first and most important performance property that needs to be considered is the tensile strength of the woven polyester fabrics. Like any building material or the material on a fabric structure, knowledge of the tensile strength is required to meet the fabric end use. These stresses are related to the pre-tension on a structure and

TABLE 8. Langmuir sorption parameters, dye affinity) and dyeing heat values of different woven polyester fabric.

\begin{tabular}{|c|c|c|c|c|c|c|c|c|c|c|}
\hline \multirow{3}{*}{$\begin{array}{c}\text { Polyester } \\
\text { type }\end{array}$} & \multicolumn{4}{|c|}{ Langmuir parameters } & \multicolumn{4}{|c|}{ dye affinity } & \multirow{2}{*}{\multicolumn{2}{|c|}{ dyeing heat values }} \\
\hline & \multicolumn{2}{|c|}{ Weft } & \multicolumn{2}{|c|}{ Warp } & \multicolumn{2}{|c|}{ Weft } & \multicolumn{2}{|c|}{ Warp } & & \\
\hline & $80^{\circ} \mathrm{C}$ & $100^{\circ} \mathrm{C}$ & $80^{\circ} \mathrm{C}$ & $100^{\circ} \mathrm{C}$ & $80^{\circ} \mathrm{C}$ & $100^{\circ} \mathrm{C}$ & $80^{\circ} \mathrm{C}$ & $100^{\circ} \mathrm{C}$ & Weft & Warp \\
\hline 5106 & -0.504 & -0.553 & -0.691 & -0.814 & -353.51 & -409.9 & $-484,7$ & -603.3 & 6.418 & -9.027 \\
\hline 4181 & -0.493 & -0.513 & -0.602 & -0.669 & -345.80 & -380.2 & -422.3 & -491.59 & 2.631 & -8.01 \\
\hline 4228 & -0.811 & -0.911 & -1.207 & -1.016 & -568.84 & -675.19 & -846.6 & -753.01 & -13.081 & -29.079 \\
\hline
\end{tabular}

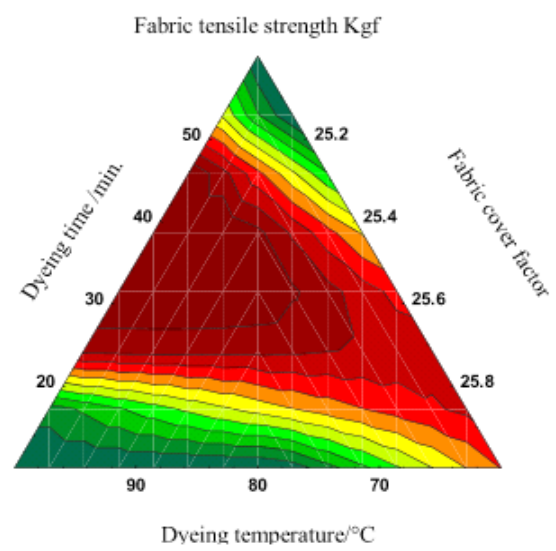

Fig. 3. Effect of temperature, fabric cover factor and time on fabric strength at break. 
must resist the forces that are applied.

Figure 3 shows the effect of temperature, fabric cover factor and time on fabric tensile strength at break. It is clear that relation presents the ideal saddle shape. Increasing fabric cover factor at middle time level and all different levels of temperature lead to increase fabric tensile strength. This effect is reversed at lower level of fabric cover factor and different levels of temperature and time.

Table 9 shows the regression analysis for fabric tensile strength at break. It is clear the multiple correlation factors is about 0.934 at a very high significant level which is a very good correlation. Fabric cover factor has strong significant effect on fabric strength (p-level 6.34E-15) as compared with other dependent variables. So contact friction between warp and weft yarns of high cover factor sample is more than other samples. This higher friction provides more resistance to tensile load. It means construction of lower cover factor samples is loose and has less binding effect of cross yarns due to decrease yarns per unit area. Thus yarn failure mechanism in the fabric is dominated with slippage of more number of yarns in lower cover factor samples as compared to higher cover factor sample.

Figure 4 shows the effect of temperature, fabric cover factor and time on fabric elongation at break. It is clear that increasing fabric cover factor at lower levels of temperature and time leads to decrease fabric elongation. This effect is reversed at high level of fabric cover factor and

TABLE 9. Regression analysis for fabric strength.

\begin{tabular}{|c|c|c|c|c|c|c|}
\hline \multicolumn{7}{|c|}{ Regression Summary for Dependent Variable: fabric strength } \\
\hline \multicolumn{7}{|c|}{$R=.96648046 R^{2}=.93408447$ Adjusted $R^{2}=.93283291$} \\
\hline \multicolumn{7}{|c|}{$F(3,158)=746.34 p<0.0000$ Std. Error of estimate: 1.6620} \\
\hline & & St. Err. & & St. Err. & & \\
\hline & BETA & of BETA & B & of $B$ & $\mathbf{t}(\mathbf{1 5 8 )}$ & p-level \\
\hline Intercept & & & 269.4247 & 8.186844 & 32.90947 & $1.82 \mathrm{E}-11$ \\
\hline Temp. & -0.7951 & 0.020425 & -0.29767 & 0.007646 & -38.9314 & 0.65946 \\
\hline $\begin{array}{c}\text { Fabric } \\
\text { cover factor }\end{array}$ & 0.1762 & 0.020425 & 0.06898 & 0.007996 & -8.62651 & $6.34484 \mathrm{E}-15$ \\
\hline Time & -0.5203 & 0.020425 & -8.14815 & 0.319858 & -25.4743 & 0.21690639 \\
\hline
\end{tabular}

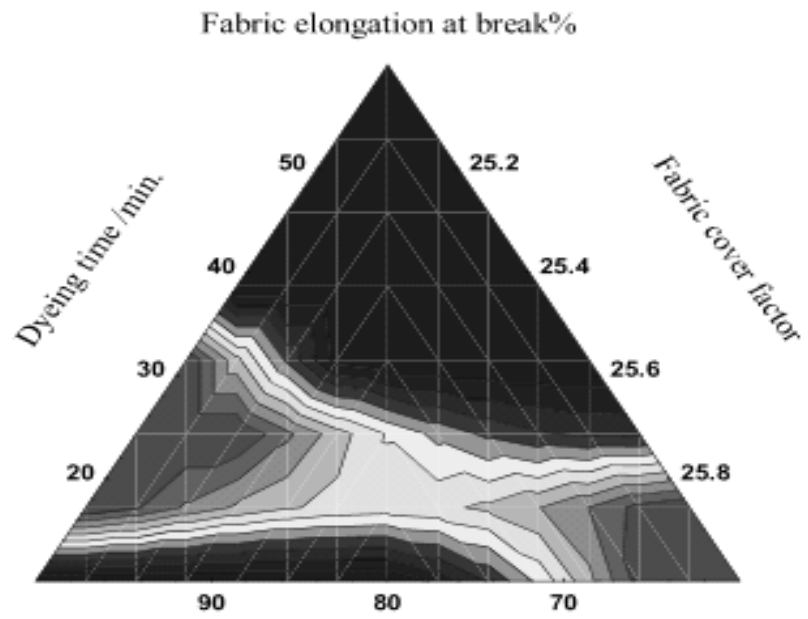

Dyeing temperature $/{ }^{\circ} \mathrm{C}$

Fig. 4. Effect of temperature, time and fabric cover factor on fabric elongation at break. 
TABLE 10. Regression analysis for fabric strength.

\begin{tabular}{|c|c|c|c|c|c|c|}
\hline \multicolumn{7}{|c|}{ Regression Summary for Dependent Variable: Elongation } \\
\hline \multicolumn{7}{|c|}{$\mathrm{R}=.77397258 \mathrm{R}^{2}=.59903355$ Adjusted $\mathrm{R}^{2}=.58881784$} \\
\hline \multicolumn{7}{|c|}{$F(4,157)=58.638 p<.00000$ Std. Error of estimate: 3.8754} \\
\hline & BETA & $\begin{array}{c}\text { St. Err. } \\
\text { of BETA }\end{array}$ & B & $\begin{array}{c}\text { St. Err. } \\
\text { of B }\end{array}$ & $\mathbf{t}(\mathbf{1 5 7})$ & p-level \\
\hline Intercept & - & - & -235.033 & 19.10401 & -12.3028 & 8.75291E-25 \\
\hline Temp. & 0.028861 & 0.050536 & 0.010648 & 0.018646 & 0.571084 & 0.568759263 \\
\hline $\begin{array}{l}\text { Fabric cover } \\
\text { factor }\end{array}$ & 0.750374 & 0.050536 & 11.07407 & 0.74582 & 14.84819 & $1.02593 E-4$ \\
\hline Time & -0.05396 & 0.050536 & -0.39815 & 0.37291 & -1.06768 & 0.287304372 \\
\hline
\end{tabular}

high levels of temperature and time.

Table 10 shows the regression analysis for fabric tensile strength at break. It is clear the multiple correlation factors is about 0.599 at a good significant level. Fabric cover factor has strong significant effect on fabric strength ( $\mathrm{p}$-level 1.02E-4) as compared with other dependent variables. So contact friction between warp and weft yarns of high cover factor sample is more than other samples. This higher friction provides more resistance to extension of fabric under load.

Finally Table 11 represents the overall color fastness properties of the dyed polyester fabric by using microwave irradiation method. The data of Table 10 reveal that the overall color fastness properties are ranged from very good to excellent in three cases of polyester fabric structures.

\section{Conclusion}

Microwave irradiation is suitable for dyeing regular and carrierless dyeable polyester fabric with different structure by selected disperse dyestuffs. The result showed that as the dyeing time as well as dyeing temperature increase the dye uptake increase and follow the order $4228>5106>4181$. Also, it is clear that as the dyeing temperature increases the dyeing rate constant increase in a similar order. Enthalpy was found to have a negative values indicating that the dyeing process is exothermic one and the values follow the same order. The color fastness properties are ranged from very good to excellent in three cases of polyester fabric structures.

Increasing fabric cover factor at middle time level and all different levels of temperature leads

TABLE 11. Fastness properties of dyed polyester fabric by microwave irradiation.

\begin{tabular}{|c|c|c|c|c|c|c|c|c|c|c|c|c|}
\hline \multirow{4}{*}{$\begin{array}{c}\text { Polyester } \\
\text { type }\end{array}$} & \multirow{2}{*}{\multicolumn{4}{|c|}{ Washing }} & \multirow{2}{*}{\multicolumn{4}{|c|}{ Rubbing }} & \multicolumn{4}{|c|}{ Perspiration } \\
\hline & & & & & & & & & \multirow{2}{*}{\multicolumn{2}{|c|}{$\begin{array}{c}\text { Acidic } \\
\text { Weft }\end{array}$}} & \multirow{2}{*}{\multicolumn{2}{|c|}{$\begin{array}{c}\text { alkaline } \\
\text { Warp }\end{array}$}} \\
\hline & \multicolumn{2}{|c|}{ Weft } & \multicolumn{2}{|c|}{ Warp } & \multicolumn{2}{|c|}{ Weft } & \multicolumn{2}{|c|}{ Warp } & & & & \\
\hline & St. & Alt. & St. & Alt. & dry & wet & dry & wet & St. & Alt. & St. & Alt. \\
\hline 5106 & 4 & $4-5$ & $4-5$ & 5 & 5 & $4-5$ & 5 & 5 & $4-5$ & 5 & $4-5$ & 5 \\
\hline 4181 & 4 & 5 & $4-5$ & $4-5$ & 5 & $4-5$ & 5 & 5 & $4-5$ & 5 & $4-5$ & 5 \\
\hline 4228 & 4 & 5 & 4 & $4-5$ & 5 & $4-5$ & 5 & 5 & $4-5$ & $4-5$ & $4-5$ & 5 \\
\hline
\end{tabular}

to increase fabric tensile strength. The regression analysis for fabric tensile strength at break showed the multiple correlation factors is about 0.934 at a very high significant level which is a very good correlation. Fabric cover factor has strong significant effect on fabric strength (p-level 6.34E-15) as compared with other dependent variables. While the regression analysis for fabric tensile strength at break showed the multiple correlation factors is about 0.599 at a good significant level. Fabric cover factor has strong significant effect on fabric strength (p-level 1.02E-4) as compared with other dependent variables. So contact friction between warp and weft yarns of high cover factor sample is more than other samples. This higher friction provides more resistance to tensile load. It means construction of lower cover factor samples is loose and has less binding effect of cross yarns due to decrease yarns per unit area. Thus yarn failure mechanism in the fabric is dominated with slippage of more number of yarns in lower cover factor samples as compared to higher cover factor sample.

\section{References}

1. Liu Li, Yeping Li, Yu Li and Yue-E. Fang, Rapid Egypt.J.Chem. Special Issue (2017) 
N-phthaloylation of chitosan by microwave irradiation. Carbohydrate Polymers, 57(1), 97-100 (2004).

2. Haggag K., Hanna H. L., Youssef B. M. and ElShimy N.S., Dyeing polyester with microwave heating using disperse dyestuffs. American Dyestuff Reporter, 84(3), 22-37 (1995).

3. Xie, Kongliang, Yanna Liu, and Xiaochun Li. Synthesis and properties of the novel surfaceactive dyes containing fluorocarbon groups: Part 1. Synthesis and surface properties of the novel surface-active dyes on silk fabric. Materials Chemistry and Physics, 105(2) 199-203 (2007).

4. Xie, Kongliang, Yanna Liu, and Xiaochun Li., Synthesis and properties of the novel surfaceactive dyes containing fluorocarbon groups: Part 2. Dyeing diffusion kinetics of the novel surfaceactive dyes on silk fabric. Materials Chemistry and Physics, 105(2), 204-207 (2007).

5. Hanna H.L., Haggag K. and El-Shimy N.S., Dyeing Polyamides using Microwave Heating with Reactive Dyestuffs, AATCC International Conference, Exhibiton, Winston-Salem, USA (2000).

6. Elshemy N.S., Mahmoud S.A., Mashaly H.M. and Haggag K., Efficient one pot synthesis of TiO2induced nanoparticles via microwave irradiation and its application in cotton dyeing with some acid dyes, Int. J. Pharm. Sci. Rev. Res., 41(2), 41-47
(2016).

7. Allen A., Fannin Handloom Weaving Technology: Revised And Updated (Design Books) Paperback - February 1, (1998).

8. AATCC, Technical Manual, Method 8 (1989), 68, 23-25 (1993).

9. AATCC, Technical Manual, Method 36 (1972), 68 (1993).

10. AATCC, Technical Manual, Method 15 (1989), 68, 30-32 (1993).

11. AATCC, Technical Manual, Method 16 A (1988), 68, 33-48 (1993).

12. Abdel-Thalouth I., Ragheb A.A., Rekaby M., El-Hennawi H.M., Shahin A.A. and Haggag. K, application of microwave in textile printing of cellulosic fabrics, Research Journal of Chemical Sciences, 4(9), 41-46 (2014).

13. El-Shemy N.S., Haggag K., El-Kharady E. and El-Sayed H.S., Synthesis and applications of nano binder based on plant oils, Journal of Natural Fibers, 14(1),10-25 (2017).

(Received 10/9/2017; accepted 19/12/2017)

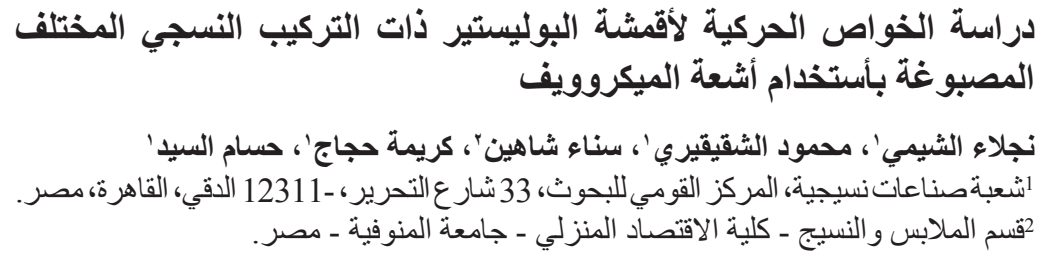

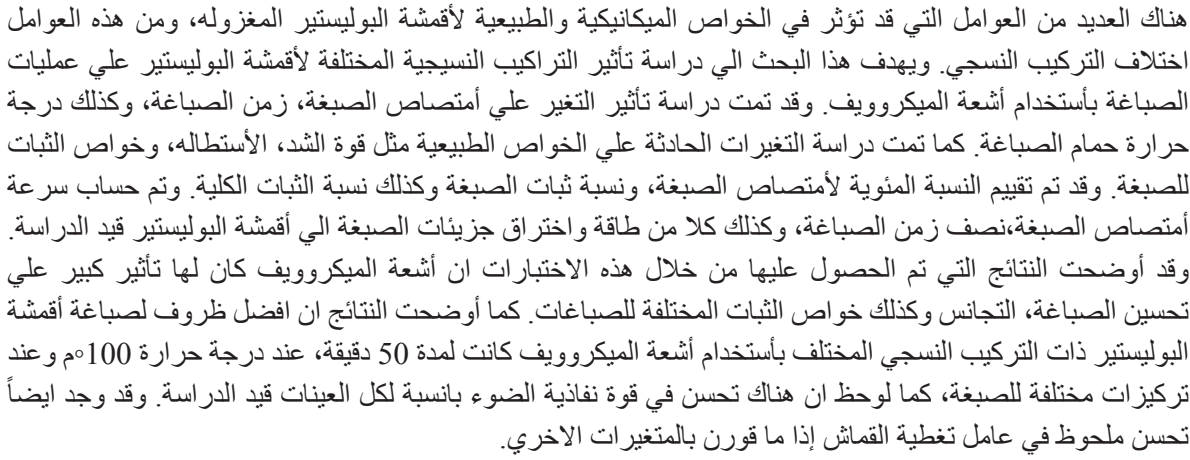

